\title{
Effect of rosuvastatin combined with trimetazidine on the cardiac function in the treatment of patients with coronary heart disease.
}

\author{
Yong-Zhong Mao ${ }^{1}$, Ling Jiang ${ }^{2 *}$ \\ ${ }^{1}$ Department of Pediatric Surgery, Union Hospital, Tongji Medical College, Huazhong University of Science and \\ Technology, Wuhan, Hubei, PR China \\ ${ }^{2}$ Department of Geriatrics, Union Hospital, Tongji Medical College, Huazhong University of Science and Technology, \\ Wuhan, Hubei, PR China
}

\begin{abstract}
Objective: This study aims to investigate the effect of rosuvastatin combined with trimetazidine in the treatment of patients with coronary heart disease.

Methods: Fifty-five cases of patients with coronary heart disease who were admitted in our department and underwent rosuvastatin therapy from December 2013 to February 2017 were selected as the control group. Another 55 cases of patients with coronary heart disease undergoing rosuvastatin combined with trimetazidine were designated as the observation group. The cardiac function indexes were analysed after the treatment.

Results: The cardiac function indexes of patients in the two groups showed significant difference after the treatment between the observation group and the control group $(\mathrm{P}<0.05)$. Blood lipid indexes $(\mathrm{TC}$, TG, HDL-C, and LDL-C) showed no significant difference before the treatment $(P>0.05)$. After the treatment, TC and LDL-C of patients in the observation group were significantly lower than that before the treatment. In comparison with the control group, a significant difference $(P<0.05)$ was observed. In the observation group, the readmission rate of myocardial infarction or angina was $9.1 \%$, which is 23.6\% lower than that in the control group; a significant difference $(P<0.05)$ was observed.

Conclusion: Rosuvastatin combined with trimetazidine therapy can improve heart function and enhance the curative effect of patients with coronary heart disease. Therefore, this combination can potentially be applied in the treatment of this disease.
\end{abstract}

Keywords: Coronary heart disease, Rosuvastatin, Trimetazidine, Cardiac function. Accepted on November 6, 2017

\section{Introduction}

Coronary heart disease is a cardiovascular disease caused by atherosclerosis [1]. The main manifestations include the decrease of the left ventricular function, as well as congestion and limitation of peripheral circulation [2]. Normally, the patient experiences arrhythmia, which induces other lifethreatening diseases. With the increase in the population of the elderly in recent years, the incidence and mortality of coronary heart disease are soaring and even evolved into a main disease in the clinic [3]. In the past, statins were applied. This medication can could improve the patients' symptoms, as well as regulate blood lipids and cardiac function indexes. However, the simple use of statins easily leads to various cardiovascular diseases, reduces the patients' quality of life, and aggravates the disease [4]. Therefore, the study for effective therapy should be further investigated. A total of 110 cases of patients with coronary heart disease in our hospital were investigated in this paper to explore the application value of rosuvastatin combined with trimetazidine therapy.

\section{Data and Methods}

\section{General information}

Fifty-five cases of patients with coronary heart disease admitted in our department and undergoing rosuvastatin therapy from December 2013 to February 2017 were selected as the control group. This group included 30 males $(54.5 \%)$ and 25 females $(45.5 \%$ ), aged $48-73$ y old (mean age, $59.5 \pm$ $1.7 \mathrm{y}$ old). Another 55 cases of patients undergoing rosuvastatin combined with trimetazidine therapy were taken as the observation group. This group included 31 males (56.4\%) and 24 females (43.6\%), aged 49-72 y old (mean age, $59.6 \pm 1.9 \mathrm{y}$ old). No difference is found in the number or average age of patients between the two groups $(\mathrm{P}>0.05)$.

\section{Inclusion and exclusion criteria}

Inclusion criteria: In accordance with the diagnosis of coronary heart disease, the patients were definitely diagnosed by ECG. 
Exclusion criteria: The patients with heart failure, malignant tumors, and drug contraindications are excluded.

\section{Methods}

The patients were treated with blood vessel dilation and oxygen support after admission. Fifty-five cases of patients were treated with rosuvastatin in the control group (manufacturer: South Shandong Beite Pharmaceutical Co. Ltd., batch number: H20080241), p.o., Qn, at $10 \mathrm{mg}$. Fifty-five cases of patients in the observation group were treated with trimetazidine on the basis of rosuvastatin in the control group (manufacturer: Hubei Sihuan Pharmaceutical Co. Ltd., batch number: H20083596), p.o., $20 \mathrm{mg}$, tid, for a total of 2 months.

\section{Observation indexes}

The cardiac function indexes were measured before and after the treatment. The occurrence of cardiovascular diseases after the treatment mainly included myocardial infarction, angina pectoris readmission, and cardiac death.

\section{Statistical methods}

The data were analysed using the SPSS18.0 statistical software. The measurement data were expressed with $\overline{\mathrm{x}} \pm \mathrm{s}$, and the t-test was performed. The count data were expressed in percentage, and the chi-square test was performed. $\mathrm{P}<0.05$ indicated statistical difference between the groups.

\section{Results}

\section{Cardiac indexes}

The cardiac function indexes (left ventricular ejection fraction and left ventricular end-diastolic dimension) in the observation group and the control group showed no statistical significance before the treatment $(\mathrm{P}>0.05)$. In Table 1 , the cardiac functions showed statistical significance after the treatment $(\mathrm{P}<0.05)$.

Table 1. Cardiac function indexes $(\bar{x} \pm s)$.

\begin{tabular}{|c|c|c|c|c|}
\hline \multirow[t]{2}{*}{ Group } & \multicolumn{2}{|c|}{$\begin{array}{l}\text { Left ventricular } \\
\text { fraction }(\%)\end{array}$} & \multicolumn{2}{|c|}{$\begin{array}{l}\text { Left ventricular end-diastolic } \\
\text { dimension }(\mathrm{mm})\end{array}$} \\
\hline & $\begin{array}{l}\text { Before } \\
\text { treatment }\end{array}$ & $\begin{array}{l}\text { After } \\
\text { treatment }\end{array}$ & $\begin{array}{l}\text { Before } \\
\text { treatment }\end{array}$ & $\begin{array}{l}\text { After } \\
\text { treatment }\end{array}$ \\
\hline $\begin{array}{l}\text { Observation } \\
\text { group }(n=55)\end{array}$ & $40.62 \pm 5.96$ & $44.58 \pm 6.39$ & $62.05 \pm 6.41$ & $51.01 \pm 5.81$ \\
\hline $\begin{array}{l}\text { Control group } \\
(n=55)\end{array}$ & $40.70 \pm 5.83$ & $47.35 \pm 6.28$ & $62.14 \pm 6.50$ & $53.96 \pm 6.24$ \\
\hline $\mathrm{t}$ & 0.071 & 2.293 & 0.073 & 2.566 \\
\hline$P$ & 0.943 & 0.024 & 0.942 & 0.012 \\
\hline
\end{tabular}

\section{Blood lipid levels between the two groups before and after the treatment}

The blood lipid levels (i.e., TC, TG, HDL-C, and LDL-C) showed no significant difference before the treatment $(\mathrm{P}>0.05)$.
The TC and LDL-C in the observation group after the treatment were significantly lower than those before the treatment. In comparison with the control group, a significant difference $(\mathrm{P}<0.05)$ is found, as shown in Table 2 .

Table 2. Blood lipid indexes before and after the treatment $(\bar{x} \pm s)$. Note: *compared with before the treatment, ${ }^{*} P<0.05 ;{ }^{\Delta}$ compared with the control group, ${ }^{\Delta} P<0.05$.

\begin{tabular}{llll}
\hline Index & Time & Control group & $\begin{array}{l}\text { Observation } \\
\text { group }\end{array}$ \\
\hline TC $(\mathrm{mmol} / \mathrm{L})$ & Before treatment & $6.21 \pm 1.21$ & $6.19 \pm 1.14$ \\
\cline { 2 - 4 } & After treatment & $5.86 \pm 1.03$ & $4.91 \pm 0.86^{*} \Delta$ \\
\hline $\mathrm{TG}(\mathrm{mmol} / \mathrm{L})$ & Before treatment & $2.35 \pm 1.75$ & $2.46 \pm 1.45$ \\
\cline { 2 - 4 } & After treatment & $1.84 \pm 0.12$ & $1.94 \pm 0.31$ \\
\hline $\mathrm{HDL}-\mathrm{C}(\mathrm{mmol} / \mathrm{L})$ & Before treatment & $1.02 \pm 0.38$ & $1.03 \pm 0.19$ \\
\cline { 2 - 4 } & After treatment & $1.12 \pm 0.68$ & $1.14 \pm 0.51$ \\
\hline LDL-C $(\mathrm{mmol} / \mathrm{L})$ & Before treatment & $3.56 \pm 1.21$ & $3.52 \pm 1.06$ \\
\cline { 2 - 4 } & After treatment & $3.62 \pm 1.02$ & $2.39 \pm 1.35^{*} \Delta$ \\
\hline
\end{tabular}

\section{Cardiovascular event occurrence}

The incidence rates of cardiovascular events were $9.1 \%$ in the observation group and $23.6 \%$ in the control group. Differences between the two groups were observed at $\mathrm{P}<0.05$, as shown in Table 3 .

Table 3. Cardiovascular event occurrence (n, \%).

\begin{tabular}{llllll}
\hline Group & $\mathbf{n}$ & $\begin{array}{l}\text { Myocardi } \\
\text { al } \\
\text { infarction }\end{array}$ & $\begin{array}{l}\text { Angina } \\
\text { readmission }\end{array}$ & $\begin{array}{l}\text { Cardiac } \\
\text { death }\end{array}$ & $\begin{array}{l}\text { Occurrence } \\
\text { rate }\end{array}$ \\
\hline $\begin{array}{l}\text { Observatio } \\
\mathrm{n} \text { group }\end{array}$ & 55 & $3(5.5)$ & $1(1.8)$ & $1(1.8)$ & $5(9.1)$ \\
\hline $\begin{array}{l}\text { Control } \\
\text { group }\end{array}$ & 55 & $8(14.5)$ & $4(7.3)$ & $1(1.8)$ & $13(23.6)$ \\
\hline $\mathrm{X}^{2}$ & & & & 4.251 \\
\hline $\mathrm{P}$ & & & & 0.039 \\
\hline
\end{tabular}

\section{Discussion}

The full name of coronary heart disease is atherosclerosis of the coronary artery, which is a heart disease of coronary stenosis or occlusion that results in myocardial ischemia and hypoxia caused by atherosclerosis of coronary artery [5]. Therefore, the coronary artery is the primary focus in this study. The body's organs depend on the nourishment of the blood, and the heart is not an exception. The heart is the central pivot of the blood circulation. The cardiac cavity is full of blood [6]. However, the heart cannot function on "first come, first served" basis and cannot directly absorb the blood nutrition from the cardiac cavity. The muscle contraction energy, growth of the heart, metabolism, and all the substances required for physiological activity are supplied by a blood vessel deriving from the aortic root. Clinical practice has 
shown that the inflammatory response plays a significant role in the pathogenesis of coronary heart disease, such as lymphocytes and granulocytes, which can help the patients with coronary heart disease [7]. Previous studies on coronary heart disease have found that the relationship between the cardiovascular disease and endothelial function is increasingly getting closer, which can aggravate the damage degree of vascular endothelial function to a certain extent and then aggravate the patient's condition. Under normal physiological conditions, the coronary circulation reserve ability is strong; the blood flow volume will change with changes in the body. However, when the coronary artery stenosis or occlusion occurs, the distention will decrease, and normal cardiac contraction is not performed; this occurrence can lead to myocardial ischemia and hypoxia. The patients may experience to the symptoms of angina.

By contrast, hyperlipidemia is an important cause of coronary heart disease. Modern medicine considered that coronary heart disease should be supplemented with lipid-lowering treatment. Statins have a strong lipid regulating effect. Hence, statins have become a common cardiovascular drug at present. Moreover, a large number of clinical studies have reported in succession [8]. However, the best dosage for treatment of coronary heart disease is controversial. Rosuvastatin, as a commonly used lipid-lowering drug, can effectively inhibit the rate-limiting enzyme of cholesterol synthesis and then prevent the synthesis of cholesterol by inhibiting its activity. Meanwhile, rosuvastatin has certain anti-inflammatory and antioxidant effects. Researchers reported that with the increase of the rosuvastatin dose, the lipid-lowering degree was also increased significantly [9]. The larger the dose is, the lower the incidence of ischemic events is. Researchers also reported that high-dose rosuvastatin $(20 \mathrm{mg} / \mathrm{d})$ can effectively reduce the total cholesterol level, and the lipid-lowering effect was significantly superior to that of the low-dose group $(5 \mathrm{mg} / \mathrm{d})$ [10]. Trimetazidine, which is a newly developed drug, can not only improve the metabolism of fatty acid but also can inhibit the generation of free radicals, maintain the normal myocardial function, and enhance the myocardial function. The combination of these two drugs can achieve significant lipidlowering effects in the treatment of coronary heart disease, which is of great significance for angina. Someone reported that after 60 cases of patients treated with trimetazidine and rosuvastatin, the total effective rate was $90 \%$; the incidence of cardiovascular events was $15 \%$, which is significantly superior to that of the simple rosuvastatin control group. In this study, the patients were treated with rosuvastatin and trimetazidine. The corresponding indexes after the treatment and the incidence of other diseases were superior to those of patients undergoing rosuvastatin therapy only, which were basically similar. Trimetazidine on the basis of rosuvastatin can better improve the cardiac function of coronary heart disease and blood lipid indexes and increase the clinical efficacy.

\section{Conclusion}

In summary, applying the treatment combination of rosuvastatin and trimetazidine to patients with coronary heart disease can improve the cardiac function and enhance the curative effect. Thus, this treatment is worthy of application.

\section{References}

1. Mufti HN, Hirsch GM. Perioperative prediction of agitated (hyperactive) delirium after cardiac surgery in adults-the development of a practical scorecard. J Crit Care 2017; 42: 192-199.

2. Zhang YM, Zhang Y, Li Z. Two novel Ni (II) complexes with two different Schiff bases: inhibiting growth of ventricular aneurysm in coronary heart disease. Lat Am J Pharm 2017; 36: 820-825.

3. Oguz N, Kirca M, Cetin A, Yesilkaya A. Effect of uric acid on inflammatory COX-2 and ROS pathways in vascular smooth muscle cells. J Recept Signal Transduct Res 2017; 3: 1-6.

4. Ren X, Zhou Y, Sun G, Sun X. Protective roles of notoginsenoside $\mathrm{R} 1$ on ischemia/reperfusion injury in isolated rat heart. Lat Am J Pharm 2017; 36: 1680-1687.

5. Saba SG, Singh J, Rahmani N, Makaryus JN. Unroofed coronary sinus: multimodality imaging of geriatric congenital heart disease. J Cardiovasc Ultrasound 2017; 25: 72-73.

6. Kalem F, Durmaz S, Ozdemir B, Ergun AG, Ertugrul O. The diagnostic value of procalcitonin, WBC, and CRP in diagnosis of lower respiratory tract infections in elderly patients. Biomed Res India 2017; 28: 1012-1015.

7. Shin SK, Cho JH, Kim EJ, Kim EK, Park DK, Kwon KA, Chung JW, Kim KO, Kim YJ. Anti-inflammatory and antiapoptotic effects of rosuvastatin by regulation of oxidative stress in a dextran sulfate sodium-induced colitis model. World J Gastroenterol 2017; 23: 4559-4568.

8. Yao C, Huang X, Li L. Perindopril improves cardiac function but not diaphragmatic fatigue in rats with chronic heart failure. Lat Am J Pharm 2015; 34: 30-35.

9. Idkaidek NM. Comparative assessment of saliva and plasma for drug bioavailability and bioequivalence studies in humans. Saudi Pharm J 2017; 25: 671-675.

10. Bala KR, Raajan NR. An approach for detecting offline intrusive attacks on biomedical information. Biomed Res India 2017; 28: 1036-1039.

\section{*Correspondence to}

Ling Jiang

Department of Geriatrics

Union Hospital

Tongji Medical College

Huazhong University of Science and Technology

PR China 